\title{
Evaluation of the Operational Performance of Continuous Green T-Intersection under Different Levels of Congestion
}

\author{
Ghayda Zawawa', Hana Naghawi²* \\ 1 Department of Consruction of Healthcare Sectore Buildings, Ministry of Public Works and Housing, Airport Road- King Abdullah \\ II Bin Al-Hussien Street, 11118 Amman, Jordan \\ 2 Department of Civil Engineering, School of Engineering, The University of Jordan, Queen Rania Street, 11942 Amman, Jordan \\ * Corresponding author, e-mail: h.naghawi@ju.edu.jo
}

Received: 16 March 2019, Accepted: 05 April 2019, Published online: 05 July 2019

\begin{abstract}
The main objective of this paper is to evaluate and compare the operational efficiency of a conventional signalized T-intersection with an unconventional Continues Green T-intersection under different congestion levels. The analysis was performed using Synchro. 8 micro-simulation software. A total of 48 hypothetical scenarios, 24 scenarios for each design, were created by changing the approach volumes and turning percentages on the major / minor intersecting roadways to reflect different levels of congestion that may occur on any urban intersection. Total intersection delay, Level of Service, maximum queue length and volume-to-capacity ratio ( $v / c)$ were the measures of effectiveness used for comparison purposes. These performance measures were selected because they demonstrated the overall efficiency of the intersection design. The simulation results showed that the Continuous Green T-intersection operates the best under stable traffic conditions and that it is not an effective solution for signalized T-intersections under heavy traffic volume. Keywords
\end{abstract}

Continuous Green T-intersection, microscopic simulation, Synchro.8, unconventional intersection design

\section{Introduction}

Efficiency of intersections contributes significantly to the efficiency and performance of highway networks. Each intersection involves through, left and right turning movements between intersecting roadways. These movements create dangerous conflict points among motorized and non-motorized interacting road users (Zheng et al., 2014). These conflicts and the unexpected heavy traffic volumes are the main source of traffic congestion, which often results in increased probability of crashes. The National Highway Traffic Safety Administration (Choi, 2010) reported that 36 percent of crashes in the United States occured at intersections. Most common intersections have three or four legs depending on the number of intersecting roadways (Chandler et al., 2013). Three-leg or T-intersections are formed when one road meets another at right or close to a right angle, one of the legs is generally a minor road connecting to a major road. Three-leg signalized intersections perform well under low to moderate traffic volumes but they poorly perform under heavy traffic volume. Transportation engineers have suggested many conventional measures to enhance the operational performance of three-leg signalized intersections such as signal timing optimization, widening on intersections, and grade separation, but the use of these conventional measures have diminishing results (Stamatiadis and Kirk, 2011). In an attempt to improve the operational efficiency and safety characteristics of the three-leg signalized intersections, the Federal Highway Administration (FHWA) (Rice and Znamenacek, 2010) proposed an unconventional intersection design named Continuous Green T-intersection (CGT-intersection). The main objective of the CGT-intersection design is to reduce the severity of potential conflicts. The CGTintersection is a signalized intersection which can only be applied at T-intersections. The general concept of the CGT-intersection is to manage traffic through:

1. providing free-flow operations in one direction on the major arterial road while the other movements are controlled with a three phases traffic signal,

2. providing auxiliary acceleration lane on the major arterial road that are separate from the through movement for the crossroad left-turn movement. 
Fig. 1 shows traffic movements on CGT-intersection. This paper evaluates and compares the operational performance of an unconventional Continuous Green T-intersection (CGT-intersection) to a conventional signalized three-leg signalized intersection under different congestion levels. For this purpose, two hypothetical intersection designs were created and simulated using Synchro. 8 microscopic traffic simulation software.

\section{Literature review}

\subsection{Continous Green T-intersection}

Many previous studies have evaluated the safety and operational efficiency of four-leg unconventional intersection designs (Hochstein et al., 2009; Moon et al., 2011; Naghawi and Idewu, 2014; Tarko et al., 2008). Few researchers studied the three-leg unconventional intersection design or CGT-intersection. Most CGT-intersection design studies were based on real traffic data. Jarem (2004) evaluated safety and operational performance of implementing five CGT-intersection designs in Orlando, Florida. He found that the delay was improved which implies economic benefits of the CGT-intersection design, also crashes that were considered to be directly related to CGT-intersection design ranged from $8 \%$ to $24 \%$ out of all crashes at the studied intersections. Also, Sando et al. (2011) assessed the safety benefits of nine CGT-intersections in Florida. It was found that crashes due to merging and diverging maneuvers are more severe than other crash types at conventional T-intersections. Rice and Znamenacek (2010) published a FHWA safety evaluation report of GCT-intersection. A before and after study was conducted on a two CGTintersection designs in Colorado. The report stated very positive safety benefits of the design; however, conclusions were formed through a very narrow scope of analysis and did not consider other intersection performance aspects. In another FHWA report, safety effects 30 CGTintersections and 38 conventional signalized T-intersections from Florida, in addition to 16 CGT-intersections and 21 conventional signalized T-intersections from South Carolina were evaluated and compared. The results showed

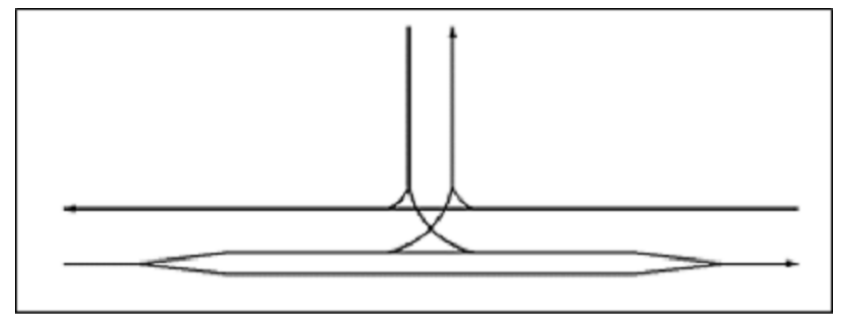

Fig. 1 Traffic Movements on Continuous Green T-intersection (Hughes et al., 2009) that there was a small but statistically insignificant benefit associated with the CGT-intersection relative to the conventional signalized T-intersection (Donnell et al., 2016). Finally, Litsas and Rakha (2013) compared the CGTintersection with the conventional T-intersection. It was found that the use of CGT-intersection decreased the total delay, fuel consumption and $\mathrm{CO}_{2}$ emission compared to the conventional T-intersection.

\subsection{Synchro}

Synchro studio is a microscopic simulation software. It is used widely for signal optimization. It implements the Intersection Capacity Utilization (ICU) method for determining intersection capacity. Synchro.8 supports the Highway Capacity Manual (TRB, 2010) methodology for signalized intersections and roundabouts. Due to its simplicity, traffic models are built within days (Trafficware, 2014).

Synchro has been extensively used by many researchers in analyzing the operational performance of many unconventional intersection designs. Hildebrand (2007) compared five unconventional intersection designs including the Bowtie, Continuous Flow, Jughandle, Median U-turn and the Superstreet using Synchro. Naghawi et al. (2018a) used Synchro and Vissim to analyze and compare the operational performance of an existing four-leg signalized intersection design to a proposed superstreet unconventional intersection design. Moon et al. (2011) used Vissim, Synchro, and Ssam simulation softwares to evaluate the operational performance and safety benefits of implementing superstreet unconventional intersection design. Naghawi et al. (2018b) used Synchro.8 to evaluated and compared the operational performance of three unconventional arterial intersection designs including Median U-turn, Superstreet, and Single Quadrant Intersection using real traffic data. The effect of implementing each of the proposed designs was not only evaluated on the isolated signalized intersection, but also on the arterial road including both surrounding intersections.

\section{Methodology}

Since constructing a live Continuous Green T-intersection and conventional T-intersection for evaluation purposes is a massive undertaking and not feasible in many circumstances. Modeling and simulation of a conventional signalized T-intersection and an unconventional CGTintersection was carried out using Synchro.8, a microsimulation software. Synchro. 8 was used as a platform to achieve two things. First, signal optimization of both intersection designs. Second, as a traffic simulation tool. 


\subsection{Geometric Design}

Bowen et al. (2014) highlighted the importance of the correct design and implementation of the CGTintersection. For this purpose, both conventional signalized T-intersection and unconventional Continuous Green T-intersection had the following geometric elements:

- Both intersections were three-leg intersections formed by two roadways, arterial and collector, crossing at a 90-degree angle.

- Both intersections were eight-lane divided arterial road intersecting with a four-lane undivided collector road.

- Each leg of the intersection was considered to be level.

- The design of each leg was extended approximately 1000 feet from the center of the intersection.

- Each intersection was designed in accordance with the Policy on Geometric Design of Highways and Streets (AASHTO, 2004) standards for a passenger car and a design speed of $45 \mathrm{mph}$.

- Lane width was considered to be $12 \mathrm{ft}$ and shoulder width was considered to be $4 \mathrm{ft}$.

- The main intersection, in both designs, was controlled by a three-phase traffic signal.

- The design was completed using computer aided design (CAD) software then it was imported into Synchro. 8 simulation software.

Fig. 2 and Fig. 3 show Synchro. 8 model for the conventional T-intersection and the unconventional CGTintersection respectively.

\subsection{Simulation scenarios}

To enable the comparison of conventional T-intersection with the CGT-intersection under different levels of congestion. A total of 48 hypothetical scenarios, 24 scenarios for each design, were created by changing the approach volumes and turning percentages on the major arterial / minor collector intersecting roadways to reflect different levels of congestion that may occur on any urban intersection. These volumes include both stable and unstable volume conditions, where a stable scenario represents a case of traffic volumes of $1200 \mathrm{vph}$ on the arterial road and an unstable scenario represents a case of traffic volume of $2000 \mathrm{vph}$ on the arterial road. These volumes were tested with $800 \mathrm{vph}$ and $1000 \mathrm{vph}$ volumes on the collector road. Also, the impact of increasing left-turn volume on the intersection performance was considered by modeling the arterial volumes with $20 \%, 30 \%$ and $40 \%$ left-turn volume on the West Bound direction, $10 \%$,

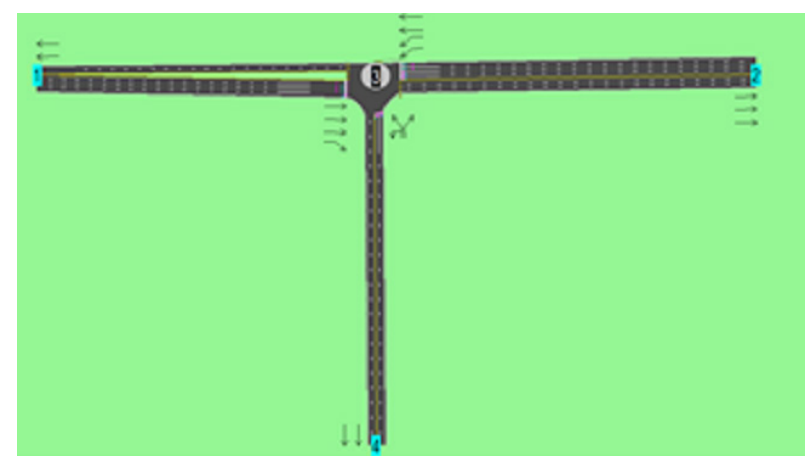

Fig. 2 Conventional T-intersection Model

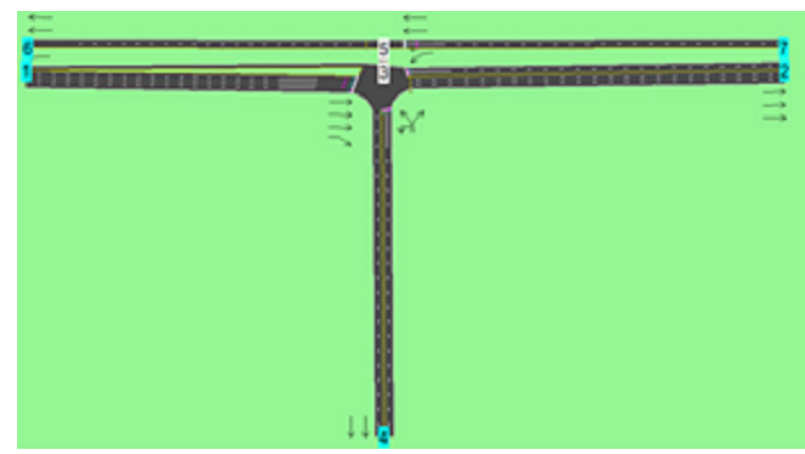

Fig. 3 Continuous Green T-intersection Model

$20 \%$ and $30 \%$ right-turn volume on the East Bound direction. Also, the collector road volumes were considered with $70 \%$ and $80 \%$ left-turn volume. Table 1 presents a summary of all traffic volumes tested in this study.

\section{Results}

Four important measures of effectiveness (MOE) extracted from Synchro.8 output results namely intersection delay, level of service (LOS), maximum queue length and the volume-to-capacity ratio $(v / c)$ were used to evaluate the efficiency of the hypnotized conventional T-intersection and the unconventional CGT-intersection designs under different traffic conditions. These performance measures were selected because they demonstrated the overall efficiency of the intersection design.

\subsection{Intersection control delay}

Intersection delay is the main measure of effectiveness that evaluates the intersection operational performance, it describes the excess time spent on the intersection due to high traffic volumes and increased cycle lengths, it is used to measure the intersection level of service. The HCM (TRB, 2010) defines LOS as a qualitative measure describing the operational conditions within a traffic stream, based on service measures such as speed and travel time, freedom to maneuver, traffic interruptions, comfort, and 
Table 1 Summary of Tested Scenarios

\begin{tabular}{|c|c|c|c|c|c|c|c|c|}
\hline \multirow{4}{*}{ Scenario } & \multicolumn{5}{|c|}{ Arterial Road } & \multicolumn{3}{|c|}{ Collector Road } \\
\hline & \multirow{3}{*}{$\begin{array}{c}\text { Traffic Volume } \\
\text { (vph) }\end{array}$} & \multicolumn{4}{|c|}{ Turning Movement (\%) } & \multirow{3}{*}{$\begin{array}{l}\text { Traffic Volume } \\
\text { (vph) }\end{array}$} & \multirow{2}{*}{\multicolumn{2}{|c|}{$\frac{\text { Turning Movement }(\%)}{\text { North Bound }}$}} \\
\hline & & \multicolumn{2}{|c|}{ East Bound } & \multicolumn{2}{|c|}{ West Bound } & & & \\
\hline & & Right & Through & Left & Through & & Left & Right \\
\hline \multicolumn{9}{|c|}{ Stable Flow Conditions } \\
\hline 1 & \multirow{6}{*}{1200} & \multirow{2}{*}{10} & \multirow{2}{*}{90} & \multirow{2}{*}{20} & \multirow{2}{*}{80} & \multirow{6}{*}{800} & 70 & 30 \\
\hline 2 & & & & & & & 80 & 20 \\
\hline 3 & & 20 & 80 & 30 & & & 70 & 30 \\
\hline 4 & & 20 & ov & 50 & 10 & & 80 & 20 \\
\hline 5 & & \multirow{2}{*}{30} & \multirow{2}{*}{70} & \multirow{2}{*}{40} & \multirow{2}{*}{60} & & 70 & 30 \\
\hline 6 & & & & & & & 80 & 20 \\
\hline 7 & \multirow{6}{*}{1200} & \multirow{2}{*}{10} & \multirow{2}{*}{90} & \multirow{2}{*}{20} & \multirow{2}{*}{80} & \multirow{6}{*}{1000} & 70 & 30 \\
\hline 8 & & & & & & & 80 & 20 \\
\hline 9 & & 20 & 80 & 30 & 70 & & 70 & 30 \\
\hline 10 & & 20 & 80 & 30 & 10 & & 80 & 20 \\
\hline 11 & & \multirow{2}{*}{30} & \multirow{2}{*}{70} & \multirow{2}{*}{40} & \multirow{2}{*}{60} & & 70 & 30 \\
\hline 12 & & & & & & & 80 & 20 \\
\hline & & & & Flow & ions & & & \\
\hline 13 & & 10 & 90 & 20 & 80 & & 70 & 30 \\
\hline 14 & & 10 & 30 & 20 & ov & & 80 & 20 \\
\hline 15 & 2000 & 20 & 80 & 30 & 70 & 800 & 70 & 30 \\
\hline 16 & 2000 & 20 & 00 & (J) & 10 & 000 & 80 & 20 \\
\hline 17 & & 30 & 70 & 40 & 60 & & 70 & 30 \\
\hline 18 & & 30 & 10 & 40 & 00 & & 80 & 20 \\
\hline 19 & & & & & & & 70 & 30 \\
\hline 20 & & 10 & 90 & 20 & ou & & 80 & 20 \\
\hline 21 & $20 \cap 0$ & 20 & 80 & 30 & 70 & مחת & 70 & 30 \\
\hline 22 & 2000 & 20 & or & 30 & 10 & 1000 & 80 & 20 \\
\hline 23 & & 30 & 70 & 40 & 60 & & 70 & 30 \\
\hline 24 & & (J) & 10 & 70 & 00 & & 80 & 20 \\
\hline
\end{tabular}

convenience. For signalized intersections level of service is defined in terms of control delay for the entire intersection. Intersection delay more than $(80 \mathrm{sec})$ indicates forced traffic conditions with LOS F.

Table 2 shows the comparison results of the Synchro. 8 analysis for the conventional signalized T-intersection and the unconventional CGT-intersection using the intersection control delay $(\mathrm{sec})$ and LOS under stable and unstable traffic conditions.

Table 2 shows that the CGT-interesection generally reduced intersection delay by $16 \%$ to $37 \%$ under all stable traffic condition scenarios, which was reflected on improving the intersection LOS. As for the unstable traffic conditions scenarios, the CGT-intersection slightly reduced the intersection delay in scenarios 15 and 16 which represent moderate left turn traffic from the arterial road with moderate traffic volume on the collector road.
Also, the CGT-intersection slightly increased intersection delay in scenarios 21 and 22 which represent moderate left turn traffic from the arterial road with high traffic volume on the collector road. Finally, Table 2 shows that the CGT-intersection significantly increased intersection delay by up to $26 \%$ in scenarios $17,18,23$ and 24 which represent high left turn volume from the arterial road. These results corresponded to breakdown conditions with LOS F. This indicates that the CGT-intersection operates the best under stable traffic conditions.

\subsection{Queue length}

In this research, the maximum queue length was also used as a performance measure of effectiveness for evaluating the performance of the unconventional CGT-intersection design when compared to a conventional signalized T-intersection. The FHWA defines queue as the storage of 
Table 2 Intersection Delay and LOS

\begin{tabular}{|c|c|c|c|c|c|}
\hline \multirow{3}{*}{ Scenario } & \multicolumn{3}{|c|}{ Control Delay (sec) } & \multicolumn{2}{|c|}{ Level of Service (LOS) } \\
\hline & \multicolumn{5}{|c|}{ Stable Traffic Conditions } \\
\hline & Conventional & CGT-intersection & Percent Reduction (\%) & Conventional & CGT-intersection \\
\hline 1 & 15.6 & 13.1 & 16.03 & B & B \\
\hline 2 & 19.2 & 14.8 & 22.92 & B & B \\
\hline 3 & 20.9 & 16.5 & 21.05 & $\mathrm{C}$ & B \\
\hline 4 & 26.6 & 18.8 & 29.32 & $\mathrm{C}$ & B \\
\hline 5 & 24.7 & 17.2 & 30.365 & $\mathrm{C}$ & B \\
\hline 6 & 32 & 20.9 & 34.69 & $\mathrm{C}$ & $\mathrm{C}$ \\
\hline 7 & 20.9 & 16.2 & 22.49 & $\mathrm{C}$ & B \\
\hline 8 & 27.4 & 19.7 & 28.10 & $\mathrm{C}$ & B \\
\hline 9 & 32 & 21 & 34.38 & $\mathrm{C}$ & $\mathrm{C}$ \\
\hline 10 & 43.6 & 28 & 35.78 & $\mathrm{D}$ & $\mathrm{C}$ \\
\hline 11 & 37.9 & 23.8 & 37.20 & $\mathrm{D}$ & $\mathrm{C}$ \\
\hline 12 & 51.3 & 32.8 & 36.06 & $\mathrm{D}$ & $\mathrm{C}$ \\
\hline \multicolumn{6}{|c|}{ Unstable Traffic Conditions } \\
\hline 13 & 45 & 37.5 & 16.67 & $\mathrm{D}$ & $\mathrm{D}$ \\
\hline 14 & 52.1 & 40.8 & 21.69 & $\mathrm{D}$ & $\mathrm{D}$ \\
\hline 15 & 77.3 & 77.2 & 0.13 & $\mathrm{E}$ & $\mathrm{E}$ \\
\hline 16 & 80.1 & 79.7 & 0.50 & $\mathrm{~F}$ & $\mathrm{E}$ \\
\hline 17 & 117.4 & 148.7 & -26.66 & $\mathrm{~F}$ & $\mathrm{~F}$ \\
\hline 18 & 119.7 & 151.1 & -26.23 & $\mathrm{~F}$ & $\mathrm{~F}$ \\
\hline 19 & 58.8 & 44.5 & 24.32 & $\mathrm{E}$ & $\mathrm{D}$ \\
\hline 20 & 74.8 & 58.7 & 21.52 & $\mathrm{E}$ & $\mathrm{E}$ \\
\hline 21 & 81.7 & 86.5 & -5.88 & $\mathrm{~F}$ & $\mathrm{~F}$ \\
\hline 22 & 92.3 & 99.9 & -8.23 & $\mathrm{~F}$ & $\mathrm{~F}$ \\
\hline 23 & 119 & 147.6 & -24.03 & $\mathrm{~F}$ & $\mathrm{~F}$ \\
\hline 24 & 128.6 & 158.9 & -23.56 & $\mathrm{~F}$ & $\mathrm{~F}$ \\
\hline
\end{tabular}

excess vehicles upstream of the bottleneck location when demand exceeds the capacity of the facility during some given time period (Hale et al., 2016).

Table 3 shows the comparison results of the Synchro. 8 analysis for the conventional signalized T-intersection and the unconventional CGT-intersection using the maximum queue length on the major arterial and the minor collector roads.

Table 3 shows that on the major arterial road, the CGTintersection design reduced maximum queue length by almost $10 \%$ to $40 \%$ under all stable traffic conditions scenarios. It also shows that, under unstable traffic conditions, the CGT-intersection reduced maximum queue length, on the arterial road, in all scenarios except scenarios 17, 18, 23 and 24 which represent high left turn volume from the arterial road. This is consistent with the increased intersection delay under these scenarios. Also, Table 3 shows that on the minor collector road, the CGT-intersection reduced the maximum queue length on the collector road by $11 \%$ to $37 \%$ under all stable traffic condition scenarios. It also shows that, under unstable traffic conditions, the CGT-intersection significantly reduced maximum queue length on the collector road by up to $28 \%$ in scenarios $13,14,15,16,19$ and 20 , but the maximum queue length in scenarios 17, 18, 21, 22, 23 and 24 was slightly reduced which represent high left turn volume from the arterial road.

\subsection{Volume-to-capacity ratio}

Volume-to-capacity ratio $(v / c)$ is the primary performance measure for highway facilities associated with determining how well a roadway is performing. It compares roadway demand (volume) with roadway supply (capacity). Generally, it is reported as decimals, according to 
Table 3 Maximum Queue Length

\begin{tabular}{|c|c|c|c|c|c|c|}
\hline \multirow{4}{*}{ Scenario } & \multicolumn{6}{|c|}{ Maximum Queue Length (ft) } \\
\hline & \multicolumn{3}{|c|}{ Arterial } & \multicolumn{3}{|c|}{ Collector } \\
\hline & \multicolumn{6}{|c|}{ Stable Traffic Conditions } \\
\hline & Conventional & CGT-intersection & Percent Reduction (\%) & Conventional & CGT-intersection & Percent Reduction (\%) \\
\hline 1 & 157 & 95 & 39.49 & 281 & 247 & 12.10 \\
\hline 2 & 119 & 95 & 20.17 & 357 & 297 & 16.81 \\
\hline 3 & 119 & 85 & 28.57 & 434 & 283 & 34.79 \\
\hline 4 & 91 & 83 & 8.79 & 334 & 297 & 11.08 \\
\hline 5 & 101 & 76 & 24.75 & 482 & 318 & 34.02 \\
\hline 6 & 121 & 83 & 31.40 & 610 & 355 & 41.80 \\
\hline 7 & 130 & 118 & 9.23 & 378 & 333 & 11.91 \\
\hline 8 & 156 & 118 & 24.36 & 460 & 401 & 12.83 \\
\hline 9 & 147 & 94 & 36.05 & 618 & 357 & 42.23 \\
\hline 10 & 156 & 127 & 18.59 & 714 & 509 & 28.71 \\
\hline 11 & 129 & 93 & 27.91 & 665 & 422 & 36.54 \\
\hline 12 & 153 & 112 & 26.80 & 838 & 559 & 33.29 \\
\hline \multicolumn{7}{|c|}{ Unstable Traffic Conditions } \\
\hline 13 & 407 & 133 & 66.99 & 382 & 275 & 28.01 \\
\hline 14 & 409 & 135 & 66.99 & 392 & 328 & 16.33 \\
\hline 15 & 330 & 164 & 50.15 & 281 & 263 & 6.41 \\
\hline 16 & 331 & 165 & 50.15 & 334 & 316 & 5.39 \\
\hline 17 & 263 & 280 & -6.06 & 269 & 263 & 2.23 \\
\hline 18 & 264 & 285 & -7.96 & 321 & 316 & 1.56 \\
\hline 19 & 434 & 135 & 68.89 & 474 & 369 & 22.15 \\
\hline 20 & 476 & 135 & 71.64 & 588 & 433 & 26.36 \\
\hline 21 & 331 & 205 & 38.07 & 374 & 369 & 1.34 \\
\hline 22 & 331 & 205 & 38.07 & 438 & 433 & 1.14 \\
\hline 23 & 262 & 290 & -9.85 & 360 & 354 & 1.67 \\
\hline 24 & 264 & 295 & -11.74 & 423 & 417 & 1.42 \\
\hline
\end{tabular}

the HCM, capacity deficiency occurs when $v / c$ value exceeds 0.90 (TRB, 2010).

Table 4 shows the comparison results of Synchro. 8 analysis for conventional signalized T-intersection and the unconventional CGT-intersection using volume-to-capacity ratio on arterial and collector roads under stable and unstable traffic conditions.

Table 4 shows that the $v / c$ ratio values on the arterial road were below 0.90 for all stable traffic condition scenarios. Also, they were slightly improved under all stable traffic conditions on the collector road. While $v / c$ ratio values indicated capacity deficiency on the arterial road and in most scenarios on the collector road under the undatable traffic conditions which implies system failure at the intersection and that the CGT-intersection fail to serve heavy traffic.

\section{Conclusion}

This main objective of this paper is to evaluate and compare the operational efficiency of a conventional signalized T-intersection with an unconventional Continues Green T-intersection using Synchro.8 simulation software. For this purpose, two Synchro. 8 models depicting the CGTintersection and a conventional T-intersection were developed and tested. Several scenarios were created by changing the approach volumes and turning percentages on the arterial / collector intersecting roadways to reflect different congestion levels resulting in a total of 48 scenarios, that's 24 for each model. Also, Synchro. 8 was used as for signal optimization of both intersection designs. Each scenario had its own independent output, and the most pertinent variables were extracted from the output and used in the analysis. The variables considered to be of primary 
Table 4 Maximum Volume-to-Capacity Ratio

\begin{tabular}{|c|c|c|c|c|}
\hline \multirow{3}{*}{ Scenario } & \multicolumn{4}{|c|}{$v / c$ Ratio } \\
\hline & \multicolumn{2}{|c|}{ Conventional T-intersection } & \multicolumn{2}{|c|}{ CGT-intersection } \\
\hline & Arterial & Collector & Arterial & Collector \\
\hline \multicolumn{5}{|c|}{ Stable Traffic Conditions } \\
\hline 1 & 0.74 & 0.86 & 0.53 & 0.70 \\
\hline 2 & 0.58 & 0.93 & 0.53 & 0.79 \\
\hline 3 & 0.40 & 0.93 & 0.42 & 0.73 \\
\hline 4 & 0.51 & 0.98 & 0.47 & 0.84 \\
\hline 5 & 0.33 & 1.00 & 0.34 & 0.78 \\
\hline 6 & 0.34 & 1.05 & 0.38 & 0.86 \\
\hline 7 & 0.65 & 0.92 & 0.60 & 0.79 \\
\hline 8 & 0.65 & 0.92 & 0.60 & 0.90 \\
\hline 9 & 0.43 & 1.04 & 0.47 & 0.89 \\
\hline 10 & 0.45 & 1.12 & 0.47 & 0.96 \\
\hline 11 & 0.36 & 1.07 & 0.38 & 0.92 \\
\hline 12 & 0.38 & 1.13 & 0.38 & 1.00 \\
\hline \multicolumn{5}{|c|}{ Unstable Traffic Conditions } \\
\hline 13 & 1.50 & 1.07 & 1.20 & 0.83 \\
\hline 14 & 1.50 & 1.10 & 1.50 & 0.95 \\
\hline 15 & 1.80 & 0.86 & 1.75 & 0.81 \\
\hline 16 & 1.80 & 0.98 & 1.75 & 0.92 \\
\hline 17 & 2.33 & 0.83 & 2.33 & 0.81 \\
\hline 18 & 2.33 & 0.95 & 2.33 & 0.92 \\
\hline 19 & 1.51 & 1.19 & 1.20 & 1.04 \\
\hline 20 & 1.65 & 1.20 & 1.29 & 1.19 \\
\hline 21 & 1.81 & 1.07 & 1.81 & 1.04 \\
\hline 22 & 1.81 & 1.23 & 1.81 & 1.19 \\
\hline 23 & 2.33 & 1.04 & 2.33 & 1.01 \\
\hline 24 & 2.33 & 1.19 & 2.33 & 1.19 \\
\hline
\end{tabular}

importance were intersection control delay, level of service, maximum queue length and volume-to-capacity ratio since these measures directly affect the intersection's performance and traffic operation. Among the general findings of this research was the CGT-intersection design consistently showed evidence of decreased delay time, improved LOS, descreased maximum queue length and improved volume-to-capacity ratio when compared to the conventional

\section{References}

American Association of State Highway and Transportation Officials (AASHTO) (2004) "Geometric Design of Highways and Streets", 5th ed., American Association of State Highway and Transportation Officials, Washington, D.C., USA. design under stable traffic conditions. The percent reduction in the intersection delay ranged from 16 to 37 percent, this delay reduction was associated with up to 40 and 37 percent reduction in maximum queue length experienced on the arterial and collector roads respectively. But unfortunately, the CGT-intersection design constantly showed capacity deficiency and system failure at the intersection under heavy traffic loading.

Bowen, A., Eubank, M., Kaiser, J., Plattner, D., Richards, G., Smith, B., Steckler, B. (2014) "Intersection Decision Guide", version 1.1, Indiana Department of Transportation (INDOT), Indiana, USA. [online] Avalilable at: https://www.in.gov/indot/files/ROP IntersectionDecisionGuide.pdf [Accessed: 03 December 2018] 
Chandler, B. E., Myers, M. C., Atkinson, J. E., Bryer, T. E., Retting, R., Smithline, J., Trim, J., Wojtkiewicz, P., Thomas, G. B., Venglar, S. P., Sunkari, S., Malone, B. J., Izadpanah, P. (2013) "Signalized Intersection Information Guide", 2nd ed., Federal Highway Administration (FHWA), U.S. Department of Transportation, Washington, D.C., USA, Rep. FHWA-SA-13-027. [online] Available at: https://safety.fhwa.dot.gov/intersection/conventional/signalized/ fhwasa13027/fhwasa13027.pdf [Accessed: 21 November 2018]

Choi, E.-H. (2010) "Crash Factors in Intersection-Related Crashes: An On-Scene Perspective", Mathematical Analysis Division, National Center for Statistics and Analysis, National Highway Traffic Safety Administration, U.S. Department of Transportation, Washington, DC, USA, Rep. DOT HS 811366.

Donnell, E., Wood, J., Eccles, K. (2016) "Safety Evaluation of Continuous Green T Intersections", Federal Highway Administration (FHWA), U.S. Department of Transportation, Washington, D.C., USA, Rep. FHWA-HRT-16-036. [online] Available at: https://www.fhwa.dot.gov/publications/research/ safety/16036/16036.pdf [Accessed: 21 November 2018]

Hale, D., Jagannathan, R., Xyntarakis, M., Su, P., Jiang, X., Ma, J., Hu, J., Krause, C. (2016) "Traffic Bottlenecks: Identification and Solutions", Federal Highway Administration (FHWA), U.S. Department of Transportation, Washington, D.C., USA, Rep. FHWA-HRT-16-064. [online] Available at: https://www. researchgate.net/profile/Jia_Hu15/publication/311667537_ Traffic_Bottlenecks_Identification_and_Solutions/ links/58ea530aaca2729d8cd59878/Traffic-BottlenecksIdentification-and-Solutions.pdf [Accessed: 11 January 2018]

Hildebrand, T. E. (2007) "Unconventional Intersection Designs for Improving Through Traffic along the Arterial Road", MSc Thesis, Florida State University.

Hochstein, J. L., Maze, T. H., Welch, T. M., Preston, H., Storm, R. (2009) "J-Turn Intersection: Design Guidance and Safety Experience", In: Transportation Research Board $88^{\text {th }}$ Annual Meeting, Washington, DC, United States, Paper Numbers: 09-0474, [DVD].

Hughes, W., Jagannathan, R., Sengupta, D., Hummer, J. (2009) "Alternative Intersections / Interchanges: Informational Report (AIIR)", Federal Highway Administration (FHWA), U.S. Department of Transportation, Washington, D.C., USA, Rep. FHWA-HRT-09-060. [online] Available at: https:/www.fhwa.dot.gov/publications/ research/safety/09060/ [Accessed: 13 September 2018]

Jarem, E. S. (2004) "Safety and Operational Characteristics of Continuous Green through Lanes at Signalized Intersections in Florida", In: ITE 2004 Annual Meeting and Exhibit, Lake Buena Vista, FL, USA, [e-book on CD-ROM] $112^{\text {th }}$ record.

Litsas, S., Rakha, H. (2013) "Evaluation of Continuous Green T-Intersections on Isolated Undersaturated Four-Lane Highways", Transportation Research Record: Journal of the Transportation Research Board, 2348(1), pp. 19-29. https://doi.org/10.3141/2348-03
Moon, J.-P., Kim, Y.-R., Kim, D.-G., Lee, S.-K. (2011) "The Potential to Implement a Superstreet as an Unconventional Arterial Intersection Design in Korea", KSCE Journal of Civil Engineering, 15(6), pp. 1109-1114.

https://doi.org/10.1007/s12205-011-1157-1

Naghawi, H. H., Idewu, W. I. A. (2014) "Analysing delay and queue length using microscopic simulation for the unconventional intersection design Superstreet", Journal of the South African Institution of Civil Engineering, 56(1), pp. 100-107.

Naghawi, H., AlSoud, A., AlHadidi, T. (2018a) "The Possibility for Implementing the Superstreet Unconventional Intersection Design in Jordan", Periodica Polytechnica Transportation Engineering, 46(3), pp. 122-128. https://doi.org/10.3311/PPtr.11635

Naghawi, H., Jadaan, K., Al-Louzi, R., Hadidi, T. (2018b) "Analysis of the Operational Performance of Three Unconventional Arterial Intersection Designs: Median U-Turn, Superstreet and Single Quadrant", International Journal of Architectural, Civil and Construction Sciences, 12(3), pp. 387-395. https://doi.org/10.5281/zenodo.1474325

Rice, E., Znamenacek, Z. (2010) "Intersection Safety Case Study: Continuous Green T-Intersections", Federal Highway Administration (FHWA), U.S. Department of Transportation, Washington, D.C., USA, Rep. FHWA-SA-09-016. [online] Available at: https://safety.fhwa.dot.gov/intersection/innovative/ others/casestudies/fhwasa09016/ [Accessed: 18 January 2018]

Sando, T., Chimba, D., Kwigizile, V., Walker, H. (2011) "Safety Analysis of Continuous Green Through Lane Intersections", Journal of the Transportation Research Forum, 50(1), pp. 5-17.

Stamatiadis, N., Kirk, A. (2011) "Improving Intersection Design Practices", Kentucky Transportation Cabinet, Frankfort, Kentucky, USA, Rep. KTC-10-09/SPR-380-09-1F.

Tarko, A. P., Inerowicz, M., Lang, B. (2008) "Safety and Operational Impacts of Alternative Intersections", Indiana Department of Transportation, Federal Highway Administration (FHWA), U.S. Department of Transportation, Washington, D.C., USA, Rep. FHWA/IN/JTRP-2008/23. [online] Available at: https://docs. lib.purdue.edu/cgi/viewcontent.cgi?article $=2661$ \& context $=$ jtrp [Accessed: 13 December 2018]

Trafficware, LLC. (2014) "Synchro Studio 9 with Warrants and TripGen 2014: Getting Started and What's New in Version 9", Trafficware, LLC., Sugar Land, TX, USA. [online] Available at: http://online.trafficware.com/downloads/pdfs/GettingStarted.pdf [Accessed: 18 February 2018]

Transportation Research Board (TRB) (2010) "HCM 2010: Highway Capacity Manual", 5th ed., Transportation Research Board, National Academies, Washington, DC, USA.

Zheng, L., Ismail, K., Meng, X. (2014) "Traffic conflict techniques for road safety analysis: open questions and some insights", Canadian Journal of Civil Engineering, 41(7), pp. 633-641. https://oi.org/10.1139/cjce-2013-0558 